\title{
Cad and Distributed Manufacturing Solutions for Pellet Boiler Producers
}

\author{
Timur Mamut ${ }^{1}$ Iuliean Hornet ${ }^{2}$ Laurentiu Oancea ${ }^{3}$, Camelia Bâcu ${ }^{4}$ \\ ${ }^{1}$ ET INNOVATIVE SOLUTIONS LTD., Cluster for Eco-technologies and alternative energy sources - \\ Medgreen, Constantza, Romania \\ 2 IULIEAN HORNET ,ECOHORNET LTD., ROMANIA. \\ ${ }^{3}$ LAURENTIU OANCEA, ET INNOVATIVE SOLUTIONS LTD, ROMANIA. \\ ${ }^{4}$ CAMELIA BACU ET, INNOVATIVE SOLUTIONS LTD, ROMANIA. \\ ${ }^{1}$ timur.mamut@et-is.eu, ${ }^{2}$ president@ecohornet.ro, ${ }^{3}$ laurentiu.oancea@et-is.eu, ${ }^{4}$ camelia.bacu@et-is.eu
}

\begin{abstract}
The paper is summarizing the research activities that had been carried out for defining an appropriate manufacturing concept and the system architecture for a manufacturing plant of pellet boilers. The concept has been validated through the implementation of a solution of computer integrated manufacturing that includes a CAD platform and a CAM facility including laser cutting machines, rolling and welding machines and advanced technologies for assembly, quality control and testing.
\end{abstract}

Keywords - computer integrated manufacturing, distributed manufacturing, pellet boilers.

\section{INTRODUCTION}

The manufacturing concepts may be considered as the core characteristic of the modern human civilization. At the same time, mankind is now facing a series of social challenges such as non-precedence growth of population, closely related to the increase of consumption, the rise of emission levels, environmental degradation and the scarcity of resources.

In the last decades, the manufacturing value chains reached a global scale. It is estimated that $80 \%$ of the global manufacturing output is concentrated in just 3 regions [1].

There are many options and there is a convergence of opinions that humanity has to move towards localized, closed loop manufacturing cycles.

For the closed loop manufacturing to be considered, it requires a fundamentally paradigm shift, from the current paradigm that starts with design, reacting at a certain scale, mass production and further to product distribution, towards the new paradigm which is called mass customization that means to design for use, to define the economic targets based on scope, to customize products and to manufacture on a distributed base all around the world.

Experts in this field are considering that researchers have to pass from current 3rd industrial revolution, which is based on extensive use of controls, IT and electronics, in order to obtain an automated and highly productive environment, towards the 4th industrial revolution [2], which is considered to be smart and based on integration of virtual and physical production systems.

In this context, what the experts call now the industry 4.0 will be based on three basic strategic goals, as convergence of applications which will form conditions of new advancements, energy efficiency and sustainability to gain greater business focus, greater presence of mobility and web-based information systems.

From the technology point of view, the 4th industrial revolution will integrate wireless technologies, internet of things, big data and cloud platforms. From the collaboration point of view, it means integrated industries, IP centralization and social innovation. In addition, from the processes perspective, it means sustainable manufacturing, integrating internet of services and life-cycle assessment. 


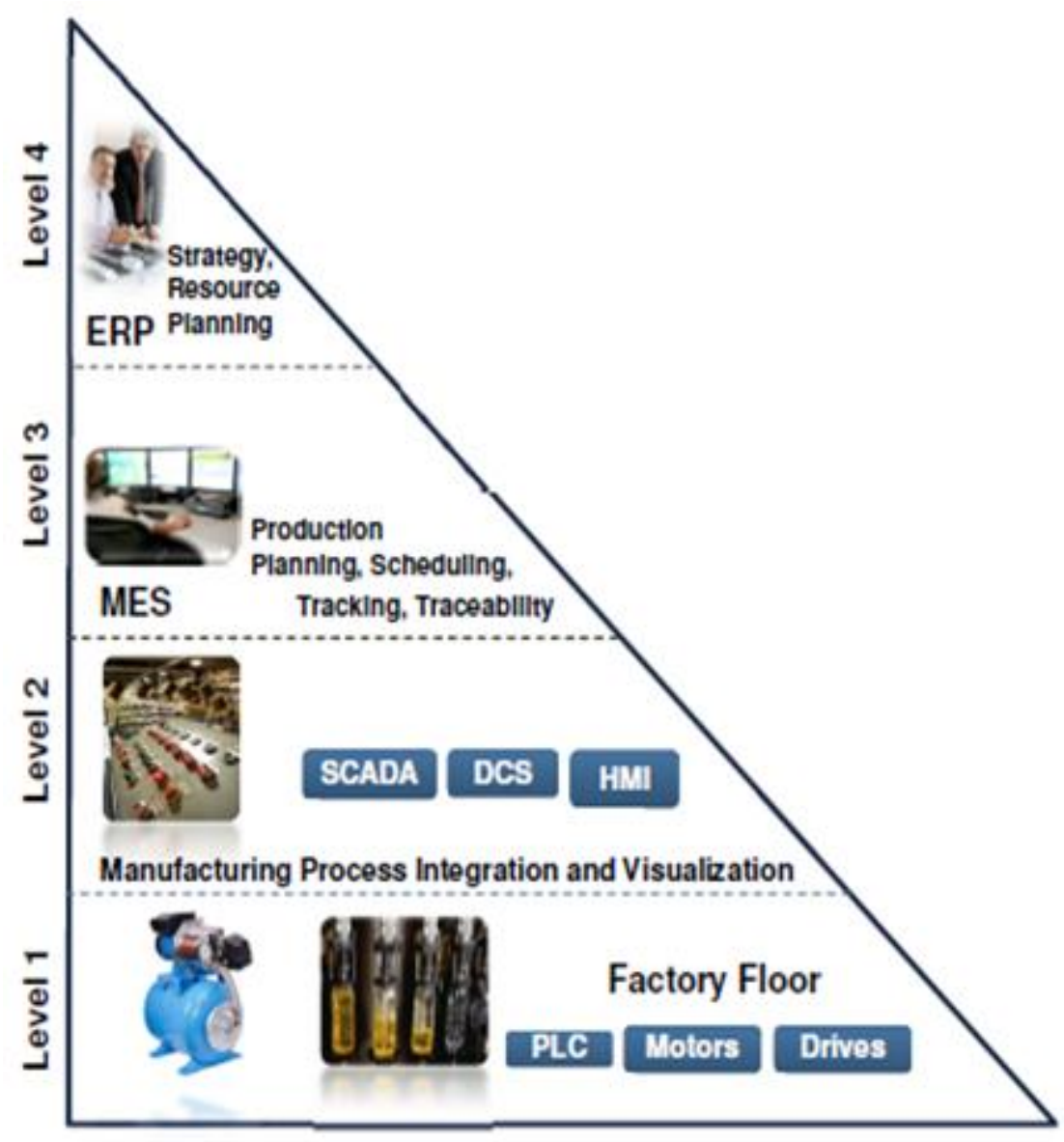

Fig .1. The enterprise pyramid [1].

According to the current status of technologies, the architecture of a manufacturing enterprise will be shaped as a pyramid with four layers. The Enterprise Pyramid is a comprehensive representation of different operational layers at their respective positions. This includes factory floor at Level 1, followed by controls and automation in Level 2, MES at Level 3, and ERP at Level 4. In a new development, product life cycle management is expected to be included in the future of enterprise hierarchy, between Levels 3 and 4 .

The companies structured following the pattern from figure 1 will be much more flexible and adaptive in integrated enterprise ecosystems. At the factory floor level, the wireless technologies will push for intelligent devices. All the industrial control systems will integrate new smart services based on mobile technologies, enabling intuitive control rooms. The manufacturing execution systems will be pushed by enterprise integration and cloud computing. The enterprise resource planning shall include software as a service and social media integration.

\section{EVALUATION OF THE CURRENT STATUS}

As a first phase in the implementation of modern enterprise architectures, a comprehensive analysis regarding the enterprise ecosystem and the specific characteristics of the existing value chain should be carried out.

For this purpose, in the specific case of the project Ecopellet, the analysis has been centered on a company specialized on manufacturing and installing of pellet boilers.

The evaluation of the enterprise ecosystem has been initiated with a SWOT analysis by the evaluation of the internal and external connectivity, including the suppliers of different components and the distribution and market delivery of the final products.

In this evaluation the market trends had been analyzed and the growth opportunities identified. The initial status of the infrastructure has been evaluated as well as the requirements for the transition to the 
modern architecture, defining optimal alternative solutions to the manufacturing phases and the evaluation of the new solutions from the technical and economical point of view.

Based on the initial evaluation, the choice for the adopted solution has been substantiated.

The project consists of three components as follows: Ecopellet Soft - is the soft component that regards the acquisition procedures, technical assistance and studies, Ecopellet core project that includes the upgrade of the manufacturing value chain and the inquiry of infrastructure components, and Ecopellet $R \& D$ that is the research component.

Ecopellet Soft project is aiming to provide technical assistance for the implementation of the investment project EcoPellet and research EcoPellet R\&D, by contracting specialized firms to carry out feasibility study, technical design, construction documentation and business plan, which will enable the efficient implementation of projects provided above.

Ecopellet core project is the investment component, aiming to develop a manufacturing line for pelletized biomass incineration system components. The new infrastructure enables accumulation of expertise by $R \& D$ activities that provide competitive advantages to the partners.

EcoPellet $R \& D$ is associated with the Ecopellet core project. The R\&D component includes industrial research, to acquire knowledge allowing the development of a competitive advantage for the partner companies. The objectives also include organizing of research activities in line with market requirements and the exploitation of research results into innovative products and services nationally and internationally competitive.

On the short term, the project aims to complete the infrastructure elements required to carry out $R \& D$ activities in the field of manufacturing pelletized biomass incinerators thus to offer competitive advantage in developing future business. This infrastructure will enable collaboration with businesses, universities and individual inventors, provision of R\&D services and implementing innovation projects. The project is also aiming to increase the performance of the manufacturing processes, the development of competitive advantages through the acquisition of high performance equipment to complement the production line, improve the quality and safety of the operation of systems for burning biomass pelleted, reduce costs and increase product competitiveness of the partner companies.

On the medium term, the project will identify specific market segments in EU countries and emerging economies. There will also be prospected emerging markets of Azerbaijan and the countries of the Caspian region, Jordan and the Middle East, Algeria and North African countries, markets with high growth potential such as Turkey, Ukraine and countries of the former Yugoslav space for the development of an expansion infrastructure.

\section{IMPLEMENTATION AND RESULTS}

In the two years of project implementation, the activities had been carried out by the project team of the two partner companies with no significant delays or setbacks.

All the steps had been carried out for the completion of the manufacturing infrastructure that included the inquiry of a laser cutting machine, a rolling machine and an advanced automated welding robot, thus assuring the optimal performance, best quality and competitive production costs.

The design department was equipped with state of the art graphic stations, running CAD CAM software. After commercial solutions have been studied, PTC Creo has been adopted as the CAD CAM software solution, for being versatile and integrating all the elements of the production process, from sketch and design, simulation, manufacturing and assembly.

Research activities have been carried out, including simulation and optimization of the burning processes, experimental research on the product range, technological planning for the new manufacturing processes. Also a test bench have been conceived and certified for the testing of various conditions of load and input of the pellet boilers.

As a result, the Ecopellet project fulfilled almost all the key point indicators and the project implementation project has ended successfully. 


\section{ACKNOWLEDGMENT}

The projects Ecopellet, Ecopellet CDI and Ecopellet Soft have been initiated by the National Competitiveness Pole on Modern Manufacturing Systems for Green Economy - MEDGreen.

The investments are funded through the Sectoral Operational Programme "INCREASE OF ECONOMIC COMPETITIVENESS" (POS CCE 2007-2013) that is co-financed by the European Regional Development Fund.

\section{REFERENCES}

[1] C. Anderson, Makers. The new industrial revolution. London: Crown Business, 2012.

[2] D. Achuthashankar. "Industry 4.0: Preparing tomorrow's digital manufacturing," in Frost \& Sulivan, Deepak Achuthashankar, Industry Analyst Industrial Automation \& Process Control, 2014.

[3] T. Mamut. "Ecoinnovative methods to exploit secondary energy resources from municipal wastewater treatment plants." $\mathrm{PhD}$ thesis, Politehnica University of Bucharest, Bucharest, 2014. 